\title{
Pentingnya Mezbah Doa Dalam Keluarga Kristen Berdasarkan 2 Samuel 24: 25
}

\author{
Septerianus Waruwu, ${ }^{1 *}$ Daniel Ginting, ${ }^{2}$ Go Heeng, ${ }^{3}$ Masran P. Hutagalung ${ }^{4}$ \\ Prodi Teologi, STT Real Batam ${ }^{1,3,4}$ \\ Prodi Misiologi, STT Real Batam ${ }^{2}$ \\ septewaruwu@gmail.com
}

\begin{abstract}
The family is the first institution formed by God in this world (Genesis 2:18), intending to be God's partner to manage the earth. Today's family challenges are quite heavy where every family faces global life with temptations that come from outside and from within the family itself. Every family longs for harmony in the family. Lately, many Christian families do not experience harmony in their families, even in the family of "God's servants". This means that there are no families without problems. Mezabah family prayer is one solution to overcome every problem that occurs in the family. Mezabah family prayer as a means to establish a relationship with God as well as with fellow family members. The importance of the family prayer altar will play a very central role in creating harmony in the family. The purpose of this paper is to offer one solution to create a harmonious family that is following God's purpose in the family through the altar of prayer based on 2 Samuel 24: 25. This research uses the method of literature review and literature research
\end{abstract}

Keywords: Altar of prayer, Family, Harmony.

\begin{abstract}
Abstrak
Keluarga adalah lembaga pertama yang dibentuk Allah dalam dunia ini (Kejadian 2:18), dengan tujuan menjadi rekan Allah untuk mengelola bumi. Tantangan keluarga masa kini cukup berat dimana setiap keluarga menghadapi kehidupan global dengan godaan yang datang dari luar maupun dari dalam keluarga itu sendiri. Setiap keluarga merindukan keharmonisan terjadi dalam keluarganya. Belakangan ini banyak keluarga Kristen yang tidak mengalami keharmonisan dalam keluarga bahkan keluarga "hamba Tuhan" juga mengalami hal yang sama. Artinya tidak ada keluarga yang tidak mengalami masalah. Mezbah doa keluarga adalah salah satu solusi untuk mengatasi setiap persoalan yang terjadi dalam keluarga. Mezbah doa keluarga sebagai sarana untuk membagun hubungan dengan Tuhan dan juga dengan sesama anggota keluarga. Pentingnya mezbah doa keluarga akan memainkan peran yang sangat sentral dalam menciptakan keharmonisan
\end{abstract}


dalam keluarga. Tujuan paper ini adalah menawarkan salah satu solusi untuk menciptakan keluarga yang harmonis yang sesuai dengan tujuan Allah dalam keluarga melalui mezbah doa berdasarkan 2 Samuel 24: 25. Penelitian ini menggunakan metode kajian literatur dan riset pustaka.

Kata Kunci : Mezbah doa, Keluarga, Harmonis

\section{PENDAHULUAN}

Gereja adalah keluarga Allah yang ada didunia. Sebagai keluarga Allah kita dimaksudkan untuk menikmati Tuhan dan menikmati relasi kasih persaudaraan di dalam kehidupan bergereja. Kita beruntung memiliki gereja untuk menjadi wadah bagi kita untuk menikmati kehidupan sebagai keluarga Allah. Namun, tidak berhenti sampai disana. Tuhan pun memberi kepada kita keluarga dalam ikatan darah dan daging. Dick menyatakan, bahwa "Keluarga adalah dua orang dewasa yang hidup bersama dan bekerjasama memelihara serta mendidik anak-anak kandung atau anak angkatnya." Dalam konsep kekristenan mengatakan bahwa, "Keluarga adalah suatu kesatuan yang amat erat. Struktur keluarga itu sendiri adalah sarana yang digunakan Allah dalam komunikasinya dengan manusia, (Kej.7:1,7,13)." " Allah membentuk keluarga serta menabiskan kelurga bukan tanpa tujuan atau pola. Dick mengatakan bahwa, "Tujuan Allah membentuk keluarga adalah dimana manusia mau tak mau akan menyadari tujuan kekal daripada citra ilahi serta penguasaan dan mengelola bumi."3 Dalam mengarungi samudera kehidupan rumah tangga tidaklah semudah apa yang orang bayangkan, tidak jarang sebuah rumah tangga terhempas gelombang badai yang akhirnya berdampak bagi keharmonisan keluarga. Tidak sedikit keluarga yang akhirnya tercerai berai tak tentu arah akibat hempasan gelombang badai, namun tidak sedikit juga keluarga yang tetap kokoh melayari samudera kehidupan rumah tangga karena mampu menjaga keharmonisan keluarga. Untuk menjaga keharomisan keluarga disinilah pentingnya membangun mezbah doa keluarga.

Saat ini ada keluarga yang sudah melupakan membangun mezbah doa keluarga karena masing-masing anggota keluarga sudah merasa sangat rohani dan berdoa sendiri tanpa perlu berdoa bersama keluarga, merasa sudah cukup mengenal Tuhan, sehingga kehilangan kesehatian dalam keluarga. Alasan sudah tidak pentingnya untuk membangun mezbah doa keluarga dikarenakan sibuk dan tidak ada waktu, sehingga ada cela bagi ibllis untuk mengambil peran sehingga tidak ada lagi hubungan intim dengan Tuhan melalui mezbah doa keluarga dan tentunya yang akan terjadi adalah hal-hal yang berlawanan dengan kehendak Allah. Ada

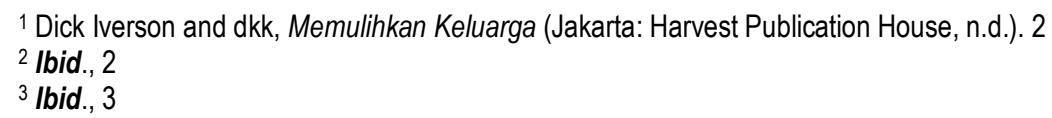


keluarga yang sedang menghadapi banyak tantangan dan ancaman yang sangat serius. Ada beberapa hal yang memicu terjadinya persoalan dalam keluarga seperti kemiskinan, ekonomi, dan gaya hidup tentunya masih ada beberapa hal menjadi sebab seperti terjadinya perselingkuhan dan juga daya tarik dunia. Bahkan komunikasi juga menjadi pemicu karena adanya dampak yang negatif dari perkembangan ilmu pengetahuan dan teknologi dan juga teknologi informatika dan komunikasi dan macam-macam tantangan lainnya. ${ }^{4}$ Seperti seorang aktifis gereja, yang kebetulan masih ada hubungan keluarga dengan penulis, pernah meminta tolong supaya menasehati anaknya laki-laki yang waktu itu masih menjadi siswa SMP, suka merokok dan berpacaran. ${ }^{5}$ Persoalan lainnya dalam keluarga adalah kaum muda Kristen yang berada di Indonesia terutama yang tinggal di kota-kota, kita melihat mereka sungguh rajin ke gereja dan melayani di hari minggu, namun dihari lain mereka suka menyakiti, membully, menjahati sesamanya, dan melakukan seks bebas, sebagaimana yang tertulis dalam Majalah Rohani Bahana. ${ }^{6}$ Bahkan aborsi juga dilakukan sebagai jalan keluar akibat perilaku seks bebas. ${ }^{7}$ Para orang tua juga tidak lepas dari sibuk mencari nafkah dan juga sibuk dengan tontonan, permainan dalam gadget sehingga tidak tertarik untuk membangun mezbah doa keluarga dan apalagi berkomitmen untuk memiliki hubungan dengan Tuhan untuk bersaat teduh maupun bersekutu bersama anggota keluarga dan akhirnya hubungan dengan Tuhan rusak. ${ }^{8}$

Berubahnya zaman dan kemajuan dalam segala aspek kehidupan berubah bahkan diwarnai banyak menjadikan kehidupan ini mudah, namun ada bahaya akan kehancuran rumah tangga, sehingga hubungan menjadi dingin dan tidak harmonis lagi akan tetap terus menjadi ancaman.. setiap anak yang diberika fasilitas hidup baik, bukan berarti anak tersebut akan menjadi generasi yang lebih baik, namun sebaliknya pengaruh dunia melalui berbagai media soasial akan menyeret anak-anak kedunia yang jauh dari harapan ${ }^{9}$ oleh karena itu pentingnya menyikapi fenomena dan tantangan-tantangan masa kini yang terekam tentang keluarga-keluarga yang tidak lagi memperhatikan betapa pentingnya mezbah doa keluarga ini. Seperti sebuah alarm bahaya sedang berbunyi untuk mengingatkan bahwa keluarga adalah penting bagi Allah. Seperti beberapa peristiwa yang terjadi dalam kehidupan hamba-hamba Tuhan dan kehilangan keharmonisan dalam keluarga. Terjadinya kehancuran keluarga dan sulit untuk

7.

${ }^{4}$ Christian Jonch, Membangun Mezbah Keluarga, 1st ed. (Yogyakarta: Penerbit ANDI, 2016). Hal. 6-

\footnotetext{
5 Stephanus Hartoyo, ARUS ZAMAN. (EKSPOSISI EFESUS 5 : 22-6 : 1-4 ), 2016.

${ }^{6}$ Gramedia, "Majalah Rohani Bahana," Majalah 198 (2017): 50-56.

${ }^{7}$ Ikhsan Bawa, "Ketika Seks Bebas Semakin Bebas," Majalah (2015).

${ }^{8}$ Christian Jonch, Membangun Mezbah Keluarga. Hal. 10

${ }^{9}$ Hartoyo, ARUS ZAMAN. ( EKSPOSISI EFESUS 5 : 22-6 : 1-4).
} 
kembali kepada Allah untuk menciptakan keluarga yang harmonis adalah sebuah persoalan yang harus diselesaikan supaya setiap keluarga Alalh kembali kepada Allah yaitu melalui mezbah doa keluarga. Dalam 2 Samuel 24:25 kita melihat bagaimana Allah mengabulkan doa Daud untuk menghentikan tulah yang akan menimpa negeri mereka. Melalui mezbah doa keluarga hal ini bias memberikan keselamatan bagi Daud dan Negerinya. ${ }^{10}$

\section{METODE}

Paper ini akan menggunakan penelitian kuantitatif untuk menjawab masalah. Merumuskan dan membatasi masalah, meninjau kepustakaan yang relevan, mendefinisikan kerangka teoritis, merumuskan hipotesis, merenungkan, berpikir, membaca, membuat konsep, revisi konsep, teoritisasi, bertukar pendapat, dan penelusuran pustaka. Penelitian kuantitatif dimulai dengan kegiatan menjajaki permasalahan yang akan menjadi pusat perhatian peneliti dan kemudian peneliti mendefinisikan serta menformulasikan masalah penelitian tersebut dengan jelas sehingga mudah di mengerti.

Mezbah pertama kali dicatat Alkitab adalah mezbah yang didirikan oleh Nuh Kej. 8:20; 9:1. Saat air bah sudah surut dan daratan sudah kering, mak Nuh sekeluarga keluar dari bahtera dan mendirikan tempat untuk menyembah Allah sebagai keprcayaannya kepada Tuhan, ucapan syukur, dan penyerahan dirinya karena Allah telah menjadi pelindung bagi dirinya dan semua keluarganya. Pendirian mezbah berlanjut pada zaman para leluhur Israel. Kemanapun mereka pergi selalu akan mendirikan mezbah bagi Tuhan untuk menyembah Tuhan. Hal berikutnya adalah saat bangsa Israel keluar dari Mesir. Allah memakai Musa untuk memerintahkan mereka supaya membangun mezbah bagi Tuhan dan juga agar mempersembahkan kurban-kurban. Dan mezbah keluarga terus dilakukan untuk penyembahan Tuhan dalam Perjanjian Lama dan berlanjut sampai ke Perjanjian Baru zaman Rasul-rasul. Kis. 21:9, Filipus mengajar dan mendidik dalam ajaran Tuhan melalui mezbah keluarga. Keluarga Prikila dan Akwila Rm. 16:3-5. Dan juga keluarga-keluarga Kristen lainnya. ${ }^{11}$

\section{HASIL DAN PEMBAHASAN}

Mezbah pertama kali dicatat Alkitab adalah mezbah yang didirikan oleh Nuh Kej. 8:20; 9:1. Saat air bah sudah surut dan daratan sudah kering, mak Nuh sekeluarga keluar dari bahtera dan mendirikan tempat untuk menyembah Allah sebagai keprcayaannya kepada Tuhan, ucapan syukur, dan penyerahan dirinya

\footnotetext{
${ }^{10}$ Andreas Loanka, "Bangun Mezbah Doa" (2017).

${ }^{11}$ Christian Jonch, Membangun Mezbah Keluarga. Hal. 37-39.
} 
karena Allah telah menjadi pelindung bagi dirinya dan semua keluarganya. Pendirian mezbah berlanjut pada zaman para leluhur Israel. Kemanapun mereka pergi selalu akan mendirikan mezbah bagi Tuhan untuk menyembah Tuhan. Hal berikutnya adalah saat bangsa Israel keluar dari Mesir. Allah memakai Musa untuk memerintahkan mereka supaya membangun mezbah bagi Tuhan dan juga agar mempersembahkan kurban-kurban. Dan mezbah keluarga terus dilakukan untuk penyembahan Tuhan dalam Perjanjian Lama dan berlanjut sampai ke Perjanjian Baru zaman Rasul-rasul. Kis. 21:9, Filipus mengajar dan mendidik dalam ajaran Tuhan melalui mezbah keluarga. Keluarga Prikila dan Akwila Rm. 16:3-5 dan juga keluarga-keluarga Kristen lainnya. ${ }^{12}$

Secara sederhana, mezbah keluarga adalah suatu tindakan yang diambil oleh seorang kepala keluarga yang untuk memimpin seluruh anggota keluarga agar menyembah Tuhan bersama-sama. Mezbah doa keluarga sebagai sarana untuk membagun hubungan dengan Tuhan dan juga dengan sesama anggota keluarga. Pentingnya mezbah doa keluarga akan memainkan peran yang sangat sentral dalam menciptakan keharmonisan dalam keluarga. Untuk memahami pentingnya dilakukan mezbah keluarga sesuai dengan 2 Sam 24: 25 sebagai dasar pembahasan dalam jurnal ini. Adapun pentingnya dan manfaat membangun mezbah doa keluarga yang di uraikan sebagai berikut:

\section{Pentingnya Mezbah Doa Keluarga}

Keluarga adalah bagian dari tatanan penciptaan Allah dan bukan bagian dari sistem sosial yang dibuat manusia. Keluarga memiliki otoritas yang diberikan oleh Allah dan membesarkan, mengajar tentang Tuhan bahkan memelihara adalah tanggungjawab orang tua. ${ }^{13}$ Setiap keluarga Kristen harus memiliki waktu untuk mezbah doa bersama atau juga disebut mezbah keluarga yang dijadwalkan. Walaupun kita sudah beribadah ke Gereja, kita tetap harus melakukan mezbah doa keluarga. Alasan mengapa penting mezbah doa keluarga karena hal ini merupakan kehendak Allah bagi keluarga khususnya orang tua yang harus mengajarkan Firman Tuhan berulang-ulang kepada anak cucu atau keluarga kita. Siapa yang harus memimpin mezbah doa keluarga? Ayah. Karena ayah adalah kepala keluarga dan juga adalah pelindung keluarga. Keluarga mesti bersatu dalam bersekutu dalam mezbah doa keluarga sehingga diharapkan akan bisa untuk menjadi kebiasaan yang menyenangkan dan menjadi gaya hidup dan kebutuhan satu

\footnotetext{
12 Ibid. Hal. 37-39.

${ }^{13}$ Anna Victoria Cahyadi \& Lim Mey Lien (Lina Gunawan) Agustinus Gea, "Peran Gereja Memperlengkapi Para Pelayannya Untuk Menjadi Para Pemimpin Yang Mentransformasi Keluarganya," SEMINAR \& KARYA ILMIAH MPDK ANGKATAN 2 (2016).
} 
keluarga. ${ }^{14}$ Mengapa pentingnya mezbah doa keluarga? Ada beberapa alasan mengapa mezbah doa itu begitu penting. Mezbah doa keluarga kita bisa dapat Bersekutu bersama Tuhan dan Keluarga. Mempunyai waktu bersama mempelajari firman Tuhan. Terlibat sebagai seorang ayah dalam mendidik anak. Membangun komunikasi dan hubungan. Oleh karena itu mezbah doa sangat penting untuk lakukan dalam keluarga supaya bisa mendidik anak, dan memuridkan keluarga agar dapat mengikut Kristus dan juga bisa melakukan Amanat Agung dalam keluarga. Bahkan dalam mezbah doa keluarga juga bisa membangun komunikasi yang baik bersama keluarga karena yang dimana kecanduan internet juga hampir merusak komunikasi sebab terlalu asyik didunia maya seolah-olah hidup di dunia nyata dan mengabaikan kehidupan yang sesungguhnya dan akhirnya masingmasing keluarga akan kekurangan komunikasi. Kita harus membangun komunikasi yang baik, lancer dan efektif. ${ }^{15}$

Pentingnya mezbah doa keluarga karena bisa bertahan menghadapi tekanan hidup. Melalui mezbah doa keluarga kita bisa bersekutu, membaca firman Tuhan dan juga bisa saat teduh. Tentunya kita harus mengandalkan Roh Kudus yang selalu memberi kekuatan dan mendukung sehingga pondasi kita kuat dalam menghadapi tekanan. Adapun juga melalui mezbah doa keluarga kita bisa saling menjaga, saling mengintropeksi diri dan saling menopang satu dengan yang lain. Persekutuan harus tetap dijaga supaya saling mengingatkan jika ada keluarga yang menyimpang dari jalan Tuhan, bersunggut-sunggut, berbuat dosa, kecewa kepada Tuhan. Dan juga bisa mengatasi pertingkaian atau konflik keluarga. Dengan demikian keluarga yang salah bisa bertobat dan saling mengampuni. Bahkan dalam juga saling mendoakan. Karena kebersamaan dalam mezbah doa keluarga selalu bisa menikmati kehadiran Tuhan dan juga merasakan keindahan berkat dalam doa keluarga. Pentingnya mezbah doa keluarga supaya bisa merasakan semua keindahan hidup dan juga memiliki komunikasi yang baik bahkan intropeksi diri, saling mengasihi bahkan harapan terbesar adalah hidup sesuai kehendak Tuhan, berkarakter seperti Kristus, meneruskan Amanat Agung dan iman kepada generasi berikutnya. ${ }^{16}$ Mezbah doa merupakan tindakan doa kepedulian terhadap kondisi komunal yang berkaitan dengan negara atau bangsa secara keseluruhan atau bahkan kebutuhan orang lain. ${ }^{17}$

${ }^{14}$ Christian Jonch, Membangun Mezbah Keluarga. Hal. 41.

15 Ibid. Hal. 44-47

${ }^{16}$ Ibid. 49

${ }^{17}$ Fredy Simanjuntak, "Mission Driven Prayer," in KIngdom Economy and Mission, 2018, 105-112, https://doi.org/10.31219/osf.io/znef2. 


\section{Manfaat Membangun Mezbah}

Daud mendirikan mezbah bagi Tuhan dan mempersembahkan korban bakaran dan korban keselamatan. Maka Tuhan mengindahkan doa untuk negeri itu, dan tulah itu ditarik dari Israel. Daud mempersembahkan korban bakaran dan persembahan perdamaian: Ini menunjukkan bahwa Daud mengerti bahwa kematian 70.000 orang di Israel dalam wabah tidak menebus dosanya dan dosa Israel. Penebusan hanya bisa dilakukan melalui penebusan darah atau cara persembahan lain di atas mezbah dimana Allah berkenan atas persembahan tersebut. Persembahan bakaran adalah untuk menebus dosa; persembahan damai adalah untuk menikmati persekutuan dengan Allah. Ini menunjukkan kepada kita dari awal hingga akhir, kehidupan Daud ditandai oleh persekutuan dengan Allah. Dari hal ini kita bisa menyimpulkan bahwa hati Tuhan tersentuh setelah Daud membangun Mezbah bagi Tuhan dan mempersembahkan persembahan dimana hal ini terjadi tentu karena intimnya persekutuan Daud dengan Allah.

Diberkati dan Intim dengan Tuhan. Abraham membagun mezbah untuk Tuhan, karena itu ia menjadi begitu akrab dengan Tuhan dan Tuhan memberkatinya dalam segala hal. Kej. 12:7-8, 24:1. Tuntunan dan penyertaan Tuhan, ketika Ishak telah mendirikan mezbah di tempatnya maka ada tuntunan dan penyertaan Tuhan saat menggali sumur untuk ternaknya. Kej. 26:25. Hadirat Tuhan, Daud mengatakan jika ingin menghadap Allah maka pergi ke mezbah Allah. Maz 43:4. Mendapatkan pernyataan Tuhan/tempat memanggil nama Tuhan Abram mendirikan mezbah bagi Tuhan dan memanggil nama Tuhan Kej. 12:8. Daud membeli tanah untuk mendirikan mezbah supaya Tulah berhenti 2 Sam 24:21. Tempat bersyukur karena delepaskan dari kesesakan Kej. 35:3.

Relevansi manfaat membangun mezbah keluarga secara spesifik tentu akan mengacu kepada setiap firman Tuhan diatas sesuai dengan manfaat yang telah diuraikan diatas. Dengan tidak menampik pada pembahasan tertentu memerlukan ayat firman Tuhan lainnya yang mendukung pelaksanaan mezbah keluarga. Dalam pelaksanaannya mezbah keluarga tentulah sangat penting karena pada saat ini, tantangan atas pernikahan dan keluarga semakin besar. Dimana terjadi semakin maraknya perceraian sampai sulitnya orangtua mengontrol keamanan anak di tengah perkembangan teknologi saat ini. Mezbah keluarga dibutuhkan saat suami, istri dan anak berkumpul bersama, menyanyikan puji-pujian, menggali firman Tuhan dan saling mendukung dalam doa. Sesuai dengan dasar firman Tuhan "Tetapi aku dan seisi rumahku, kami akan beribadah kepada Tuhan (Yosua 24: 15). Karena dosa akibat keluarga yang tidak harmonis semakin serius maka mezbah keluarga sangat penting dilakukan. Tujuan iblis adalah menghancurkan keluarga dengan merusak hubungan keluarga dan melahirkan pertengkaran antara suami dengan istri, orangtua dengan anak serta anak dengan anak. Dampak dari dosa 
terhadap keutuhan keluarga akan tercermin dengan hilangnya sukacita dan damai sejahtera saat berada di rumah dan saat bercengkerama. ${ }^{18}$

\section{Tujuan Mezbah Doa Keluarga}

Tuhan membentuk keluarga ada tujuan dan rencana yang indah bagi keluarga. Kehendak Tuhan adalah keluarga Kristen bertumbuh dan hidup didalam Dia serta memiliki hubungan yang baik, intim, dan harmonis dengan sesama anggota keluarga. Untuk itu, kita harus membangun keluarga sesuai tujuan-Nya melalui mezbah doa keluarga. Tujuan utama mezbah doa keluarga supaya senantiasa menyembah dan memuliakan Allah. Anggota keluarga perlu dididik supaya mengetahui bahwa kita mengasihi mereka dan juga saudara seiman kita dan juga yang belum percaya. Tujuan lain selain menyembah dan memuliakan Allah, hidup kita juga mesti penuh dengan pujian dan ucapan syukur yang tulus supaya Allah senang dan juga mengakui keberadan Allah dan segala keagungan-Nya serta kebesaran-Nya. Disamping itu melalui mezbah doa keluarga kita juga membangun satu keluarga yang hidup di tengah-tengah dunia yang semakin tidak mudah. Mezbah doa keluarga juga memiliki tujuan supaya keluarga kita bisa selalu menjadikan Tuhan adalah Tuhan dan pusat dari segala aspek dalam hidup ini. Oleh karena itu perlunya kita menjadikan Tuhan sebagai kepala dalam keluarga kita. Hal ini penting supaya kita hanya berfocus kepada Tuhan dan mengarahkan kepada Tuhan yang akan memenuhvvi hati kita dan menjadi dasar dalam keluarga kita. Untuk mencapai tujuan tersebut tentunya keluarga kita harus senantiasa taat kepada Allah dan firman-Nya dan membiarkan Roh Kudus memenuhi, menguasai, dan memimpin hidup kita. Dengan demikian maka Roh Kudus akan memampukan keluarga kita untuk tidak berbuat dosa dan selalu menghasilkan buah Roh. Roh Kudus akan memimpin kita melalui banyak hal seperti memberi kuasa, meneguhkan kita, menguatkan kita, membimbing, mengajar, bersaksi, dan melayani-Nya. ${ }^{19}$

Melakukan mezbah doa keluarga akan membawa dampak yang signifikan dalam kehidupan sehari-hari. Khususnya sebagai seorang ayah adalah kepala keluarga yang bertanggungjawab untuk memastikan anak-anak bertumbuh kembang dalam pengasuhannya dan juga dapat menjadi motivator yang tiada hentinya saat anak membutuhkan bahkan mendapat kasih sayang dan juga pada hakekatnya menjadikan keluarga bisa menghadapi segala sesuatu. Tentunya dalam hal ini bisa berakar, bertumbuh, berbuah secara holistik. Dengan demikian anggota keluarga dapat berpegang pada kebenaran. Ini adalah salah satu solusi untuk

${ }^{18}$ Andreas Loanka, "Bangun Mezbah Doa."

${ }^{19}$ Christian Jonch, Membangun Mezbah Keluarga. Hal. 56-58 
menciptakan keluarga yang harmonis yang sesuai dengan tujuan Allah dalam keluarga melalui mezbah doa.

\section{KESIMPULAN}

Pentingnya mezbah doa keluarga telah dibahas diatas dan tentunya mempunyai dasar firman Tuhan yang kuat dan Tuhan rindu agar anggota keluarga harus beribadah, bersekutu bersama-Nya dan membina, membangun satu keluarga yang harmonis supaya mampu bertahan untuk melewati berbagai tantangan masa kini. Untuk itu, kita harus menyadari baik itu dalam gereja dan juga di sekolah Kristen tidak bisa melakukan tugas untuk keluarga namun sebagai keluarga Kristen harus terlibat dalam membangun mezbah doa keluarga sebagaimana yang dirancangkan oleh Tuhan yang tujuanya agar keluarga dapat bersekutu bersama untuk memuji, menyembah Allah dan melaksanakan kehendak dan Amanat Agung ditengah-tengah dunia ini. Membangun mezbah doa keluarga supaya merasa lebih dekat dengan Tuhan dan menjalani hidup dalam kehendak Tuhan. Sebagai orang tua meneruskan firman Tuhan kepada anggota keluarga agar mereka terus dapat bertumbuh kembang secara holistik dan berakar didalam hidup dan bersemi kepada generasi selanjutnya. Dengan memperhatikan kepentinngan dan tujuan mezbah doa keluarga marilah kita melakukannya menjelang hari Tuhan yang semakin dekat. $^{20}$

\section{KEPUSTAKAAN}

Agustinus Gea, Anna Victoria Cahyadi \& Lim Mey Lien (Lina Gunawan). "Peran Gereja Memperlengkapi Para Pelayannya Untuk Menjadi Para Pemimpin Yang Mentransformasi Keluarganya." SEMINAR \& KARYA ILMIAH MPDK ANGKATAN 2 (2016).

Andreas Loanka. "Bangun Mezbah Doa" (2017).

Christian Jonch. Membangun Mezbah Keluarga. 1st ed. Yogyakarta: Penerbit ANDI, 2016.

Gramedia. "Majalah Rohani Bahana." Majalah 198 (2017): 50-56.

Hartoyo, Stephanus. ARUS ZAMAN . (EKSPOSISI EFESUS 5 : 22-6 : 1-4), 2016.

Ikhsan Bawa. "Ketika Seks Bebas Semakin Bebas." Majalah (2015).

Iverson, Dick, and dkk. Memulihkan Keluarga. Jakarta: Harvest Publication House, n.d.

Simanjuntak, Fredy. "Mission Driven Prayer." In KIngdom Economy and Mission, 105-112, 2018. https://doi.org/10.31219/osf.io/znef2.

20 Ibid. Hal. 143-145 